\title{
Enhancing the Stability of SEIG Connected Distribution System Using Reactive Power Control Capabilities of DFIG under Varying Wind Speeds
}

\author{
Kalyan Raj Kaniganti ${ }^{1}$ and Srinivasa Rao Rayapudi ${ }^{2}$ \\ 1. Department of Electrical and Electronics Engineering, Gudlavalleru Engineering College, Andhrapradesh 521356, India \\ 2. Department of Electrical and Electronics Engineering, JNTUK, Kakinada, Andhrapradesh 533003, India
}

\begin{abstract}
The increased level of penetration of wind generators into modern power system has significant effect on network operation. The time varying nature of wind speed has significant effect on performance of wind generator, therefore efficient mechanism for stabilizing the output of the wind generator is very much needed. Self-excited induction generators (SEIG) already existing in the network are sensitive to wind speeds. In this paper, a new method for voltage control of SEIG utilizing reactive power enhancing capabilities of doubly-fed induction generator (DFIG) is simulated and its effect on the network is analyzed for varying wind speeds. The choice of placing DFIG adjacent to SEIG or at another bus is also addressed in this paper with simulation results. The results show that this method of utilizing the reactive power capabilities of DFIG enhances voltage stability of SEIG as well as system stability.
\end{abstract}

Key words: Self excited induction generator, doubly fed induction generator, capacitance, stabilization, reactive power requirement, load flow analysis.

\section{Introduction}

The injection of wind turbine generating unit (WTGU) into passive distribution networks has become a common practice in recent times. The variable nature of wind shows a significant effect on generator behaviour as well as connected load, which is to be thoroughly examined before integration. The injection of WTGU model in load flow analysis has been studied in numerous works [1, 2]. Since the level of WTGU penetration into distribution system is increasing day by day, the model of asynchronous machine is still of interest if we can assess reactive power output accurately. In many of the cases, generator models are considered assuming that generator output power matches with machine rated power, which is not achieved practically. Many models like P-X model are proposed to handle this

Corresponding author: Kalyan Raj Kaniganti, Ph.D., assistant professor, research fields: power flow modeling of electrical machines and power system optimization. issue [3]. Detailed analyses of different WTGU models are discussed in Refs. [4-6]. Eminoglu et al. [7] introduced a novel non iterative method of incorporating wind turbine into distribution system with some simplifications. Butler [8] introduced a 3- $\phi$ load flow for shipboard power systems handling multiple sources. The work done in the above literature concentrated on incorporating DG into load flow with an assumption of constant output power at rated voltage. Since the input parameter wind is variable in nature, it has significant effect on the generator characteristics and hence on the system into which it is injected. Only few attempts $[9,10]$ are made to study the effect of scenarios like under excitation of the generator, reactive power handling capabilities of WTGU and their effect on the integrated system.

In DFIG system, the generator can be used to deliver or expend reactive power through magnetization provided by the rotor-side converter [11]. Clearly, this could further enhance the effect on 
power system stability due to increased level of wind generators penetration, moreover, if this could be possible without extra cost. However limited efforts were made to study the impact of reactive power control mode of DFIG on the power system. DFIGs are getting to be more generally utilized because of their progressed reactive power and voltage control capacity. DFIGs make utilization of power electronic converters and are, in this way, ready to regulate their own reactive power keeping in mind the end goal to work at a given power factor and to control the grid voltage [12]. On the other hand SEIG which already exists in network does not have this nature of self regulating both voltage and reactive power during varying wind speeds and fault conditions. This is because, voltage build up of machine depends upon value of capacitance connected across stator terminals which supplies necessary reactive power for the machine to self-excite. The value of capacitance to be connected depends upon generator speed which varies during wind speed and fault conditions. At a point when voltage control necessity is beyond the ability of SEIG, voltage stability of a grid will be influenced. Many methods are proposed in this context for voltage control of SEIG, but each method has its own pros and cons. The proposed methods are discussed in detail and compared in Ref. [13]. A DFIG installed into a network having SEIG can supply the reactive power requirement of SEIG retaining its generating capability and also increases system stability.

The investigation with DFIG in distribution system application in this context of reactive power control mode has no enough significance in literature. In this paper an attempt is made to study issues like influence of under-excited SEIG on network and reactive power handling capabilities of DFIG when added to network. For this a new methodology of resenting DFIG in terms of its equivalent capacitance is proposed to study the reactive power handling capabilities of DFIG and its ability to stabilize SEIG, thereby improving the network stability.
The outcomes of the paper can be summarized as follows:

(1) Power flow model (PQ-Model) for SEIG and DFIG are developed.

(2) Enhancing the low voltage ride through capability of SEIG already existing in the network with adjacent DFIG.

(3) Reactive power flow model of DFIG is developed to study its capabilities and effect on the distribution system.

(4) Cost effective solution for voltage control of distribution system without additional equipment.

The rest of the paper is organized as follows: Section 3 describes power flow modeling of SEIG, DFIG and reactive power control mode of DFIG; Section 4 presents optimal location of DG units for minimum power loss and minimum voltage deviation using genetic algorithm; Section 5 addresses the effect of SEIG and DFIG on power system during varying wind speeds; Section 6 explains the effect of reactive power control mode of DFIG on bus voltage and power loss of the network along with under excited SEIG; Section 7 gives the conclusions.

\section{Modeling of WTGU for Power flow Analysis}

In this paper two types of generators with different performance characteristics are considered. One is the SEIG which is sensitive to varying wind speeds and draw reactive power, other is DFIG which can withstand variation in wind speed and has the ability to produce reactive power. The power flow models of these two generators are discussed below.

\subsection{Self-Excited Induction Generator}

When a capacitor bank is connected across stator terminals of induction machine driven by a prime mover, say wind turbine, it acts as a generator. From literature it is observed that voltage build up is very much depending upon magnetizing reactance and excitation capacitance connected across the machine, 
which is decided by the value of generator speed and load resistance [14]. So, minimum capacitance requirement of SEIG for different wind speeds is to be calculated for analysing power flow characteristics. The load is kept at 1 p.u (full load), as the generator is made to operate at full load in most of the conditions. The minimum capacitance requirement for a given wind speed is calculated by following equations:

$$
\begin{gathered}
C_{\text {min }}=\frac{1}{2 \prod}\left(\frac{X_{L} a}{M_{3}}+\frac{M_{4}}{M_{1}^{2}+M_{2}^{2}}\right) \\
M_{1}=R_{s} R_{r}-f(f-v) L_{1} \\
M_{2}=R_{r} f L_{3}+R_{s}(f-v) L_{2} \\
M_{3}=R_{L}^{2}+X_{L}^{2} f^{2} \\
M_{4}=R_{r} M_{2}+L_{2} f(f-v) M_{1}
\end{gathered}
$$

In this section the point of interest is to study the nature of voltage build up in SEIG when the wind speed is varying. So, capacitor value is fixed which is equal to capacitance required during rated speed. The minimum capacitance requirement per-phase at different generator speeds is shown in Table 1.

From results it is observed that as generator speed increases capacitance value required for generator to self-excite decreases. As long as reactive power requirement of SEIG is satisfied it generates power at rated voltage or else the SEIG falls into under excited region and fails to build voltage. The corresponding active and reactive power output of the generator is calculated using Eqs. (6) and (7) respectively.

$$
\begin{gathered}
P_{e}=\frac{s R_{r} V^{2}}{R_{r}^{2}+s^{2}\left(X_{s}+X_{r}\right)^{2}} \\
Q_{e}=\frac{A}{B}
\end{gathered}
$$

where $\mathrm{A}$ is expressed as:

$$
\left[X_{m} X_{r} s^{2}\left(X_{m}+X_{r}\right)+X_{s} s^{2}\left(X_{m}+X_{r}\right)^{2}+R_{s}^{2}\left(X_{m}+X_{s}\right)\right] y^{2}
$$

and $B$ is expressed as:

$$
\begin{aligned}
& {\left[R_{s} R_{r}+s\left(X_{m}^{2}-\left(X_{m}+X_{r}\right)\left(X_{m}+X_{s}\right)\right)\right]^{2}+} \\
& {\left[R_{r}\left(X_{m}+X_{s}\right)+s R_{s}\left(X_{m}+X_{r}\right)\right]^{2}}
\end{aligned}
$$

In actual scenario, the value of capacitor bank connected across SEIG is fixed. So, reactive power should be supplied externally for the machine to reach its voltage build up requiremnts. In this paper a new

\begin{tabular}{|c|c|c|c|c|c|c|}
\hline $\begin{array}{l}\text { Wind } \\
(\mathrm{m} / \mathrm{s})\end{array}$ & $\begin{array}{l}\text { Generator } \\
\text { speed } \\
(\mathrm{rad} / \mathrm{s})\end{array}$ & $\begin{array}{l}\text { Speed } \\
\text { (p.u) }\end{array}$ & $\begin{array}{l}\mathrm{Vt} \\
\mathrm{kV} \text { (per phase) }\end{array}$ & $\begin{array}{l}\text { Excitation } \\
\text { capacitance } \\
\text { (p.u) }\end{array}$ & $\begin{array}{l}\mathrm{P}_{\mathrm{e}} \\
(\mathrm{MW})\end{array}$ & $\begin{array}{l}\mathrm{Q}_{\mathrm{e}} \\
(\mathrm{kVAr})\end{array}$ \\
\hline 12 & 157.5 & 0.9 & 1.36 & 1.0 & 0.65 & 23 \\
\hline 10 & 133 & 0.85 & 1.00 & 1.0 & 0.27 & 3 \\
\hline 9.5 & 125 & 0.8 & Voltage collapse & 1.0 & -- & -- \\
\hline 9 & 117 & 0.75 & Voltage collapse & 1.0 & -- & -- \\
\hline 8 & 102 & 0.7 & Voltage collapse & 1.0 & -- & -- \\
\hline
\end{tabular}
method of suppling reactive power from DFIG for voltage control of SEIG is proposed and its effect on the network is analysed in following sections. For a fixed excitation capacitance value, the performance charecterstics of SEIG at different wind speeds are presented in Table 2.

Table 1 Capacitance requirement of SEIG for different generator speeds.

\begin{tabular}{lll}
\hline $\begin{array}{l}\text { Wind speed } \\
(\mathrm{m} / \mathrm{s})\end{array}$ & $\begin{array}{l}\text { Generator speed } \\
(\mathrm{rads} / \mathrm{s})\end{array}$ & $\begin{array}{l}\text { Minimum capacitance } \\
(\mu \mathrm{F})\end{array}$ \\
\hline 12 & 157.5 & 68 \\
10 & 133 & 83 \\
9.5 & 125 & 90 \\
9 & 117 & 98 \\
8 & 102 & 106 \\
\hline
\end{tabular}

Table 2 Performance of SEIG at different wind speeds. 
The generator speeds presented in Table 2 are the steady state generator speeds and it varies during the transient state (period before satisfying the reactive power requirement of SEIG). From the results it is observed that with fixed capacitance and reducing wind speed, generator fails to excite when wind speed is below $10 \mathrm{~m} / \mathrm{s}$ and leads to voltage collapse. In addition, at under excitation the generator acts as a reactive load on bus to which it is connected and tries to draw reactive power from the network.

\subsection{Doubly Fed Induction Generator}

The model of DFIG used in this paper is steady state model $[15,16]$ which is independent of $d-q$ reference frame. It reduces the complexity in drawing the characteristics of DFIG and this model resembles the exact behaviour of DFIG. The two inputs required for the model are stator voltage and wind speed. The rotor voltage, stator and rotor power equations are given in Eqs. (8)-(16). Solving Eqs. (8) to (10) gives the value of $V_{r}, I_{s}$ and $I_{r}$. Placing the values of stator and rotor currents and voltages in Eqs. (11) to (16) we can obtain the performance characteristics of DFIG at different wind speeds.

$$
\begin{gathered}
V_{s} \angle \psi_{s}=\left(R_{s}+j\left(X_{s}+X_{m}\right)\right) I_{s} \angle \phi_{s}-j X_{m} I_{r} \angle \phi_{r} \\
V_{r} \angle \psi_{r}=\left(R_{r}+j\left(X_{r}+X_{m}\right)\right) I_{r} \angle \phi_{r}-j X_{m} I_{s} \angle \phi_{s}
\end{gathered}
$$

The relation between stator and rotor voltage is given by:

$$
V_{r}=j L_{r} \omega_{s l i p} I_{r}+\frac{L_{m}}{L_{s}} s V_{s}
$$

The real and reactive power output of the grid side VSC reaching the point of common coupling (PCC) is given by:

$$
\begin{aligned}
& P_{r}=\operatorname{real}\left\{V_{s}\left[\frac{V_{s}-V_{r}}{Z_{g}}\right]^{*}\right\} \\
& Q_{r}=\operatorname{imag}\left\{V_{s}\left[\frac{V_{s}-V_{r}}{Z_{g}}\right]^{*}\right\}
\end{aligned}
$$

The real and reactive powers of the induction generator are given from the following equations:

$$
\begin{gathered}
P_{s}=\operatorname{real}\left(V_{s}\left(I_{s}\right)^{*}\right) \\
Q_{s}=\operatorname{imag}\left(V_{s}\left(I_{s}\right)^{*}\right)
\end{gathered}
$$

The total active and reactive power output of DFIG is

$$
\begin{aligned}
& P_{e}=P_{s}+P_{r} \\
& Q_{e}=Q_{s}+Q_{r}
\end{aligned}
$$

From the above equations total power output and rotor voltage of DFIG obtained for different wind speeds are presented in Table 3 .

From Table 3, it is observed that, unlike SEIG, DFIG generates power even at wind speed of $8 \mathrm{~m} / \mathrm{s}$. This is achieved by controlling the frequency of voltage and power injected from rotor side. The power factor obtained at different wind speeds is close to 0.99. This shows that model developed is constant power factor model which can be easily injected into power flow studies.

\subsection{Method for Voltage Control of SEIG}

In DFIG, presence of back to back converter configuration makes it capable of controlling reactive power output. From literature it is clear that reactive power output of DFIG depends on rotor side converter current limit. Since power electronic converters used for power control are capable of withstanding currents up to $150 \%$ of rated value [11], the reference of rotor side converter current is changed depending on reactive power requirement. To achieve this analytically a new term " $\mathrm{K}$ " is introduced in the performance equations of DFIG. The value of $I_{r}$ in Eqs. (9) and (10) is replaced by new term $I_{r, \text { new }}$ as given in Eq. (17). The value of " $\mathrm{K}$ " is changed in incremental steps of 0.05 between 1.0 and 1.5 until reactive power output matches with reactive power requirement of SEIG. The value of reactive power is converted into the 
Table 3 Performance of DFIG at different Wind speeds.

\begin{tabular}{llll}
\hline Wind speed $(\mathrm{m} / \mathrm{s})$ & Generator speed $(\mathrm{rads} / \mathrm{s})$ & $\mathrm{P}_{\mathrm{e}}(\mathrm{MW})$ & $\mathrm{Q}_{\mathrm{e}}(\mathrm{kVAr})$ \\
\hline 8 & 102 & -0.22 & 9.03 \\
9 & 117 & -0.26 & 10.2 \\
9.5 & 125 & -0.31 & 13.4 \\
10 & 133 & -0.34 & -19.3 \\
12 & 157.5 & -0.64 & -23.9 \\
14 & 188 & -1.07 & -18.4 \\
16 & 212 & -1.5 & -69.53 \\
\hline
\end{tabular}

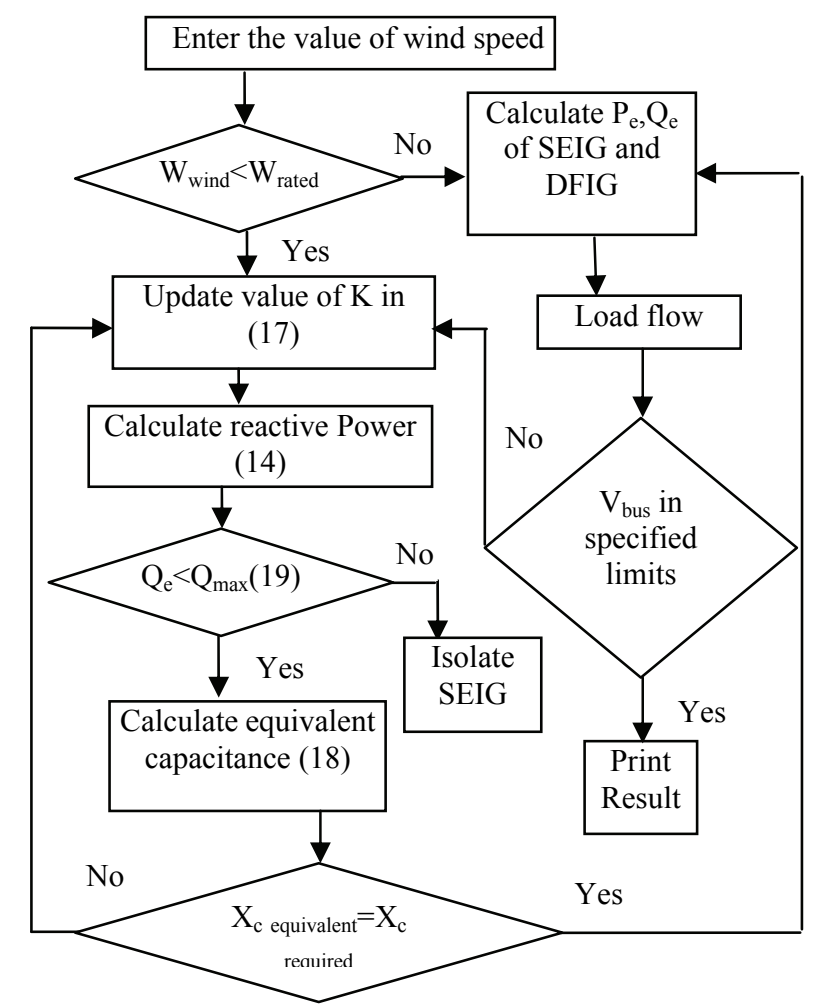

Fig 1 Flow Chart for reactive power control mode of DFIG.

equivalent capacitance using Eq. (18). $\mathrm{I}_{\mathrm{r}, \text { new }}$, which resembles the reference value of rotor side converter current, is varied until equivalent capacitance value matches the required capacitance. The maximum reactive power output $\left(\mathrm{Q}_{\max }\right)$ of rotor side converter is limited by Eq. (19). The algorithm for deriving equivalent capacitance of DFIG is explained in Fig. 1.

$$
\begin{gathered}
I_{r, \text { new }}=I_{r} * K \\
X_{c}=Q_{a b c} / \operatorname{imag}\left(I_{s}^{2}\right) \\
Q_{\max }=\sqrt{S_{t}^{2}-P_{r}^{2}}
\end{gathered}
$$

The value of equivalent capacitance of DFIG obtained is added to the fixed capacitance value connected across SEIG. The value obtained in Table 4 is added to fixed excitation capacitance of $68 \mu \mathrm{F}$. The value obtained at different speeds is equal to minimum capacitance value required for self excitation given in Table 1. This shows the validation of proposed model and SEIG generates power at rated voltage.

The results show that by increasing current limit of rotor side converter, reactive power produced increases and hence enhances the capabilities of DFIG. As wind speed reduces, rotor side converter is made to draw current from the utility grid and injects more reactive currents on stator side and thus equivalent capacitance 
Table 4 Equivalent capacitance of DFIG during reactive power control mode at different wind speeds.

\begin{tabular}{lllll}
\hline $\begin{array}{l}\text { Wind speed } \\
(\mathrm{m} / \mathrm{s})\end{array}$ & $\begin{array}{l}\text { Generator speed } \\
(\mathrm{rad} / \mathrm{s})\end{array}$ & $\begin{array}{l}\text { Rotor side converter } \\
\text { current }\end{array}$ & $\begin{array}{l}\text { Equivalent capacitance } \\
(\text { per phase) } \\
(\mu \mathrm{F})\end{array}$ & $\begin{array}{l}\text { Capacitance } \\
(\mathrm{p} . \mathrm{u})\end{array}$ \\
\hline 12 & 157.5 & $\mathrm{I}_{\mathrm{r}, \text { new }}=\mathrm{I}_{\mathrm{r},}$ & 10.2 & 0.15 \\
10 & 133 & $\mathrm{I}_{\mathrm{r}, \text { new }}=\mathrm{I}_{\mathrm{r}}$ & 15.5 & 0.23 \\
9.5 & $\mathrm{I}_{\mathrm{r} \text {,new }}=1.24 \mathrm{I}_{\mathrm{r}}$ & 22.56 & 0.32 \\
9 & 125 & $\mathrm{I}_{\mathrm{r}, \text { new }}=1.45 \mathrm{I}_{\mathrm{r}}$ & 30.3 & 0.43 \\
8 & 117 & $\mathrm{I}_{\mathrm{r}, \text { new }}=1.48 \mathrm{I}_{\mathrm{r}}$ & 37.4 & 0.55 \\
\hline
\end{tabular}

value increases.

\section{Optimal Location of WTGU}

The planning of power system in the presence of WTGU is very important and it depends on technology being used, number and capacity of units and more importantly location of the unit. In this paper, the test system considered for analysis of proposed method is IEEE 33 bus radial distribution system [4] given in Fig. 2.

The integration of wind turbine (WT) has influence on system voltage profile, power loss and stability of the system which is to be carefully evaluated [17]. The allocation of WT in inappropriate locations can lead to effect opposite to the desired. Many methods are proposed for optimal location of distributed generators [17-19] in distribution system. Before location the size of WTGU is taken as 1.5 MW each and wind speed of $8-14 \mathrm{~m} / \mathrm{s}$ is considered in this work and required parameters of WTGU are given in Appendix. In this paper, genetic approach is used to find optimal location of the WT. Since the size of WT is considered as $1.5 \mathrm{MW}$ in the analysis, the fitness function is to be derived for optimal location of wind turbines. The fitness function is selected to reduce power loss and cumulative voltage deviation. The fitness function for optimal location of WT is determined as:

$$
F=W_{p} * P_{l}+W_{q} * Q_{l}+W_{v} * C V D
$$

The active and reactive power losses are obtained from load flow program. Because of limited use of matrix operations, the forward and backward sweep method is selected for load flow in this paper. Convergence occurs when calculated source voltage in the backward sweep corresponds to specified source voltage. The cumulative voltage deviation resembles the deviation of bus voltage from specified ( 1 p.u) value is given by Eq. (25).

$$
\begin{gathered}
P_{i_{\text {new }}}=P_{i_{\text {old }}}-\left(P_{D G}\right) \\
Q_{\text {inew }_{\text {new }}}=Q_{\text {i old }}-\left(Q_{D G}\right) \\
P_{\text {loss }}=i_{\text {bus }}{ }^{2} * r_{\text {bus }} \\
Q_{\text {loss }}=i_{\text {bus }}^{2} * x_{\text {bus }} \\
C V D=\left|\sum_{i=1}^{n}\left(1-V_{i}\right)\right|
\end{gathered}
$$

where $\mathrm{W}_{\mathrm{p}}, \mathrm{W}_{\mathrm{q}}, \mathrm{W}_{\mathrm{v}}$ are objective function weights of active power loss, reactive power loss and voltage deviation such that:

$$
W_{p}+W_{q}+W_{v}=1
$$

The selection of proper weighting values depends on priorities and experience of the system planner [20, 21]. For the problem discussed in this paper, priority

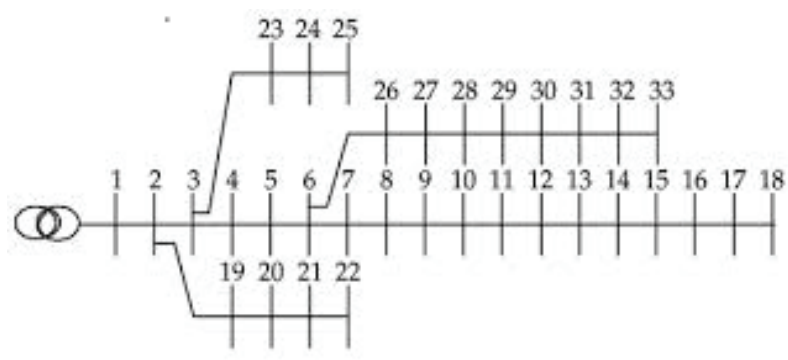

Fig. 2 IEEE-33 bus radial distribution system. 
is given to minimum voltage deviation compared to active and reactive power loss. Considering the previous reports [20-22] more weight is given for minimum voltage deviation $(0.55)$ and then for active power loss (0.35) and finally reactive power loss (0.1). The main constraints in load flow analysis are power loss constraint and voltage constraint given as:

$$
\begin{gathered}
\mathrm{P}_{\text {Loss with DG }}<\mathrm{P}_{\text {Loss }} \\
\mathrm{Q}_{\text {Loss with DG }}<\mathrm{Q}_{\text {Loss }} \\
\mathrm{V}_{\text {bus_min }}<\mathrm{V}_{\text {bus }}<\mathrm{V}_{\text {bus_max }}
\end{gathered}
$$

Single point binary cross over and polynomial mutation is adopted in this paper. Two WT generators are considered in this paper, one acting as SEIG and the other as DFIG both of 1.5 MW. Two scenarios are considered one of which is, when two generators are connected at different buses and the other is when two generators are connected at same bus. The results obtained from genetic algorithm approach for optimal location of generators in both scenarios are shown in Table 5. All the voltage values tabulated in section IV and $\mathrm{V}$ are per unit (p.u) values.

From Table 5, the best location when generators are connected at different buses (scenario 1) is at 8 and 29. The minimum voltage obtained is 0.9612 at bus 18 and power loss is reduced to $98.26 \mathrm{~kW}$. The power loss and minimum voltage in the base case of the system is $211 \mathrm{~kW}$ and 0.9036 at bus 18 respectively. When two generators are connected at same bus (scenario 2), the best location obtained is bus 6 . The minimum bus voltage obtained is 0.9561 at bus 18 and total power loss is $110.6 \mathrm{~kW}$. Losses in scenario 2 are more compared to Scenario 1 because, when two generators are placed at same bus, the loss at this bus increases thereby influencing overall losses. Even though power loss at generator bus is high compared to base case, overall power loss decreases. The rest of the analysis is done by keeping the bus location fixed which is obtained from genetic algorithm.

\section{Results}

Since aim of the paper is stabilizing existing SEIG systems, DFIG used for voltage control can be installed in two ways i.e. to connect DFIG at bus other than SEIG bus and second is at bus in which SEIG is already connected. The optimal location of wind turbines in both scenarios is determined as given in the previous section.

\subsection{Scenario1}

In Scenario 1, generators are connected at bus 8 and 29 in order to get optimal power flow solution with minimum power loss and maximum bus voltage. The SEIG is placed at bus 8 and DFIG is placed at bus 29 as shown in Fig. 3. When wind speed reduces to the value of $12 \mathrm{~m} / \mathrm{s}$ and the minimum bus voltage is 0.9364 at bus 18 . The voltage at bus 8 is 0.9594 and at bus 29 is 0.959 . The total power loss is $106 \mathrm{~kW}$. But when speed is further reduced to $8 \mathrm{~m} / \mathrm{s}$ the scenario changes completely and SEIG starts to draw reactive power from the grid in order to maintain its generating capability as indicated in Fig. 3.

The minimum bus voltage falls to 0.8970 which is less than base case because, when wind speed is less than the base speed reactive power is drawn $\left(\mathrm{Q}_{\text {drawn }}\right)$ by SEIG form grid for voltage build up. The value of reactive power drawn is given by Eq. (26). The value of $\mathrm{X}_{\mathrm{c} \text { Required }}$ in Eq. (27) is given in Table 1 .

Table 5 Optimal location of DG in scenario 1 and scenario 2 from GA.

\begin{tabular}{llllll}
\hline Scenario & $\begin{array}{l}\text { Optimal locations } \\
\text { (bus) }\end{array}$ & Min voltage & Min voltage bus & Voltage at DG bus & Power loss $(\mathrm{kW})$ \\
\hline No DG & -- & 0.9036 & 18 & -- & 211 \\
Scenario 1 & 8 and 29 & 0.9612 & 18 & 0.9816, & 98.26 \\
Scenario 2 & 6 & 0.9567 & 18 & 0.9807 & 110.6 \\
\hline
\end{tabular}



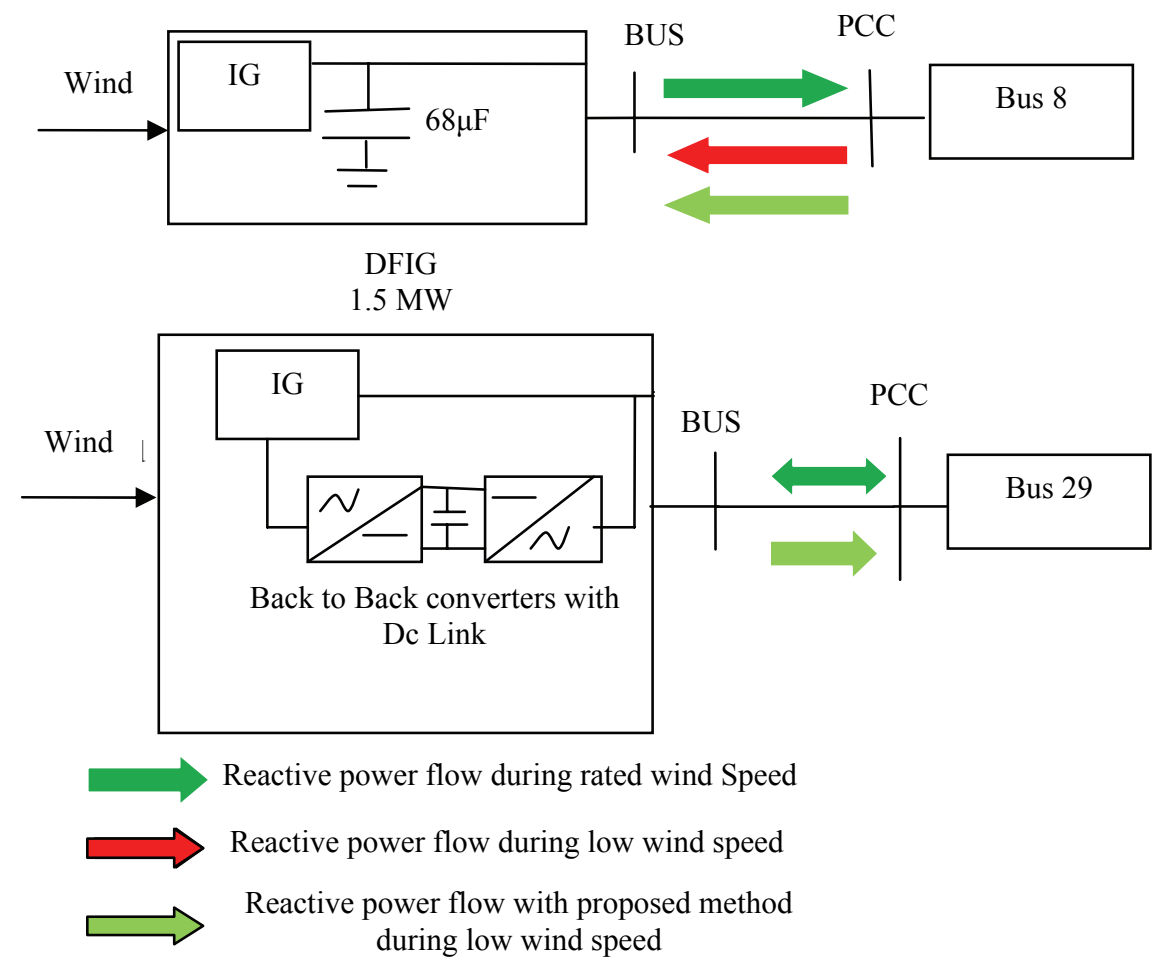

Fig. 3 Reactive power flow during scenario 1 for different wind speeds.

$$
\begin{gathered}
Q_{\text {drawn }}=V_{\text {bus }}{ }^{2} / X_{C_{\text {Drawn }}} \\
X_{C_{\text {Drawn }}}=X_{C_{\text {Re quired }}}-X_{C_{\text {Base }}}
\end{gathered}
$$

SEIG at bus 8 tries to draw a reactive power of 325 kVAr which can be obtained from Eqs. (26) and (27) to maintain its generating capability. The voltage at bus 8 is 0.9272 and at bus 29 is 0.9281 . The power loss reaches to $191.8 \mathrm{~kW}$ which is nearer to the base case as shown in Table 6 . In this case the buses 7 to 18 are highly affected and it leads to drop in entire system as shown in Fig. 4. In general practice SEIG is isolated from the system to protect it from voltage drop. But by proposed method, stability of the system can be enhanced without disconnecting SEIG as explained in following sections.

\subsection{Scenario 2}

For scenario 2, both wind turbines are to be connected at bus 6 as shown in Fig. 5. At rated wind speed of $14 \mathrm{~m} / \mathrm{s}$, minimum bus voltage is 0.9561 at bus 18. The voltage when both wind turbines are connected at bus 6 is 0.9876 and total power loss of the system is $110.6 \mathrm{~kW}$. When wind speed reduces to $12 \mathrm{~m} / \mathrm{s}$, minimum bus voltage is 0.95 at bus 18 and voltage at bus 6 is 0.967 .

When wind speed reduces further to $8 \mathrm{~m} / \mathrm{s}$, minimum bus voltage falls to 0.902 , but voltage at wind turbines connected bus (bus 6) is 0.9485 as shown in Fig. 6. Though SEIG draws a reactive power of 325 $\mathrm{kVAr}$, voltage of wind turbines connected bus is close to specified limit because DFIG is connected adjacent to the SEIG which is capable of injecting active power.

The total power loss of the system increases to 210 $\mathrm{kW}$. The power loss at bus 6 is high which causes increase in overall power loss given in Table 7 .

\subsection{Variation of Bus Voltages during Reactive Power Control Mode of DFIG}

When two generators are at different buses i.e., at 8 

Capabilities of DFIG under Varying Wind Speeds

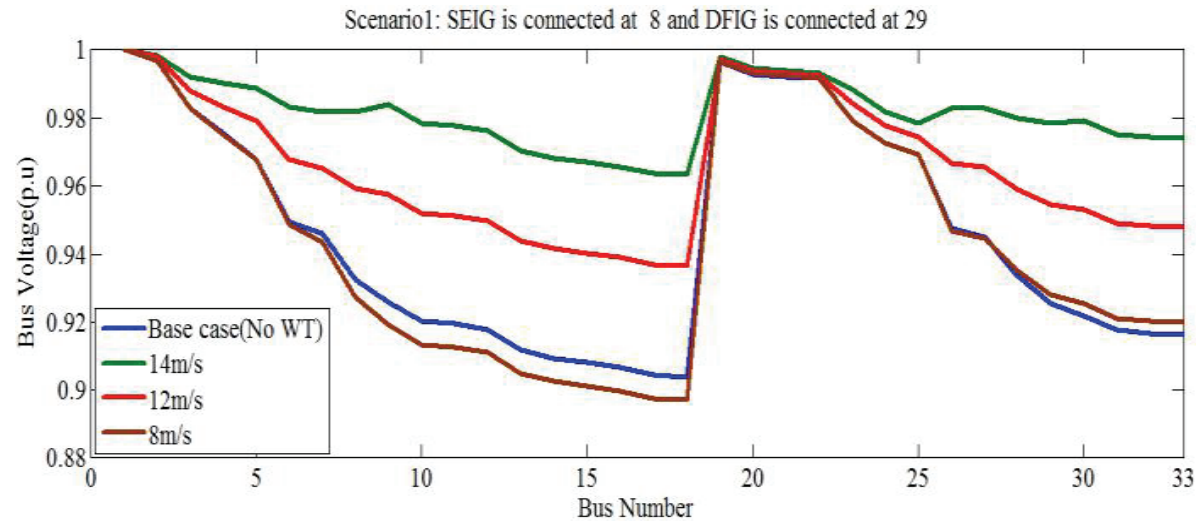

Fig. 4 Voltage profile for different wind speeds during scenario 1.

Table 6 Performance of the system during different wind speeds in scenario1.

\begin{tabular}{llllll}
\hline $\begin{array}{l}\text { Wind speed } \\
(\mathrm{m} / \mathrm{s})\end{array}$ & Min bus voltage & Bus number & $\begin{array}{l}\text { Voltage at WT } \\
\text { bus at } 8\end{array}$ & $\begin{array}{l}\text { Voltage at WT } \\
\text { bus at 29 }\end{array}$ & $\begin{array}{l}\text { Power loss } \\
(\mathrm{kW})\end{array}$ \\
\hline No DG & 0.9036 & 18 & 0.9381 & 0.9289 & 211 \\
14 & 0.9612 & 18 & 0.9816 & 0.9801 & 98.26 \\
12 & 0.9364 & 18 & 0.9594 & 0.9589 & 106 \\
8 & 0.8970 & 18 & 0.9327 & 0.9281 & 191.8 \\
\hline
\end{tabular}

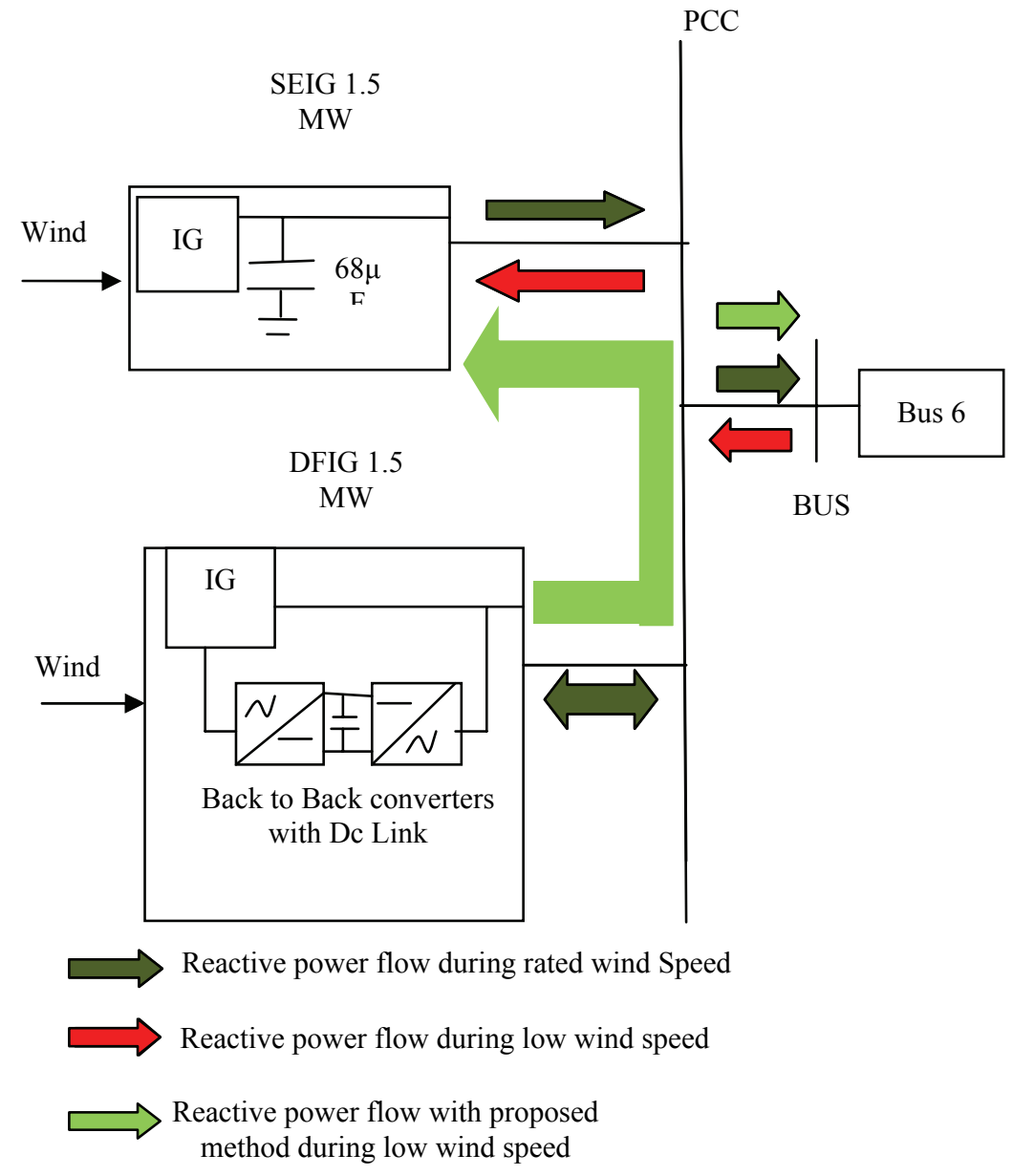

Fig. 5 Reactive power flow during scenario 2 for different wind speeds. 


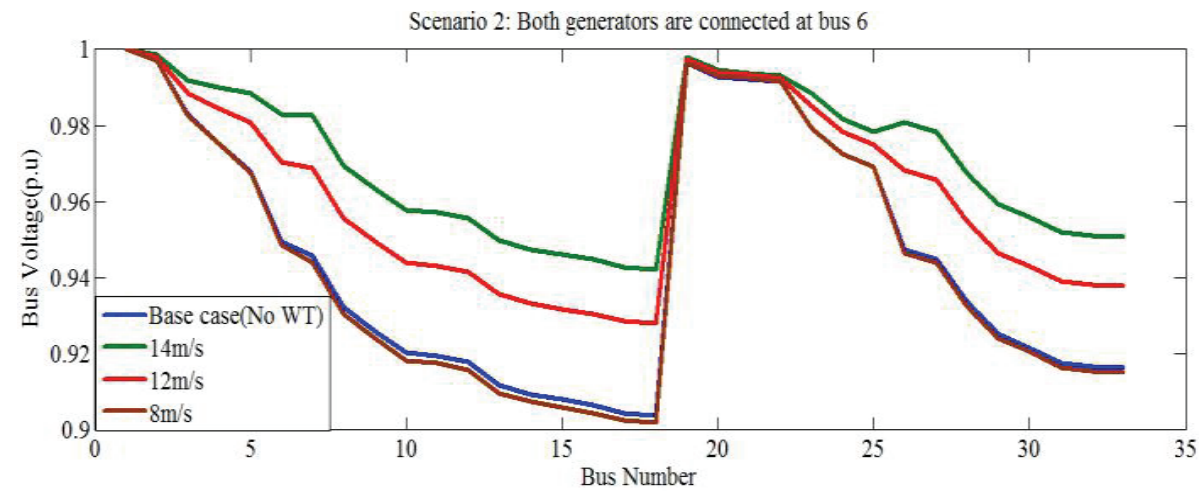

Fig. 6 Voltage profile for different wind speeds during scenario 2.

Table 7 Performance of the system during different wind speeds in scenario 2.

\begin{tabular}{lllll}
\hline Scenario & Min voltage & Bus number & Voltage at DG bus (6) & $\begin{array}{l}\text { Power loss } \\
(\mathrm{kW})\end{array}$ \\
\hline Without DG & 0.9036 & 18 & 0.9475 & 211 \\
$14 \mathrm{~m} / \mathrm{s}$ & 0.9561 & 18 & 0.9878 & 110.6 \\
$12 \mathrm{~m} / \mathrm{s}$ & 0.9240 & 18 & 0.9671 & 133 \\
$8 \mathrm{~m} / \mathrm{s}$ & 0.9020 & 18 & 0.9485 & 210 \\
\hline
\end{tabular}

and 29 (Scenario 1), DFIG generates necessary reactive power of $325 \mathrm{kVAr}$ and injects this power into network. The SEIG at bus 8 draws the reactive power of $325 \mathrm{kVAr}$ to generate power at rated voltage. The processes of injecting and absorbing of reactive power from different buses take place autonomously as shown in Fig. 3. From Fig. 7, it is observed that minimum voltage is 0.9101 at bus 18 , but voltage at SEIG connected bus (bus 8) is 0.9366 and voltage at DFIG connected bus (bus 29) is 0.9401 . The losses are reduced to $168 \mathrm{~kW}$, which is not very less compared to previous case because there is a high power loss both at bus 8 and bus 29 during power injection and absorption shown in Table 8.

When the generators are connected to the same bus (scenario 2), the reactive power required by the SEIG is supplied by the DFIG locally as indicated in Fig. 5. From Fig. 8, it is seen that minimum bus voltage is 0.9194 at bus 18 and the voltage at bus 6 is 0.955 . The power loss is reduced to $160 \mathrm{~kW}$ where as it is $204 \mathrm{~kW}$ in previous case. The proposed method in both cases works well but each case has its pros and cons which are discussed in detail in Section 6.

The comparison of both cases is shown in Fig. 9. It is observed that the voltage profile improvement in scenario 2 is more compared to scenario 1 because the reactive power required by the SEIG is supplied locally.

\section{Effect of Scenario 1 and Scenario 2 on Nearest Buses}

When SEIG is absorbing reactive power from network it shows a significant effect on bus to which WT is connected as well as on the buses nearer to WT connected. In this paper, an attempt is made to analyze the effect WT integration (scenariol and scenario 2) on nearest buses. During Scenario 1 when wind speed reduces to $8 \mathrm{~m} / \mathrm{s}$, SEIG at bus 8 starts drawing reactive power from network. Along with bus 8, the other nearest buses 9, 10 and 11 experience a significant voltage drop which can be seen from Table 9. In contrast buses 5 and 7 do not experience much effect though they are nearer. The bus 6 is not influenced much, since it is connected to a lateral as it receives power from the DFIG connected at bus 29. When proposed method is applied, buses 9, 10 and 11 are highly benefited as compared to buses 5, 6 and 7. The buses nearer to bus 29, where DFIG is connected are also affected as shown in Table 9. 

Capabilities of DFIG under Varying Wind Speeds

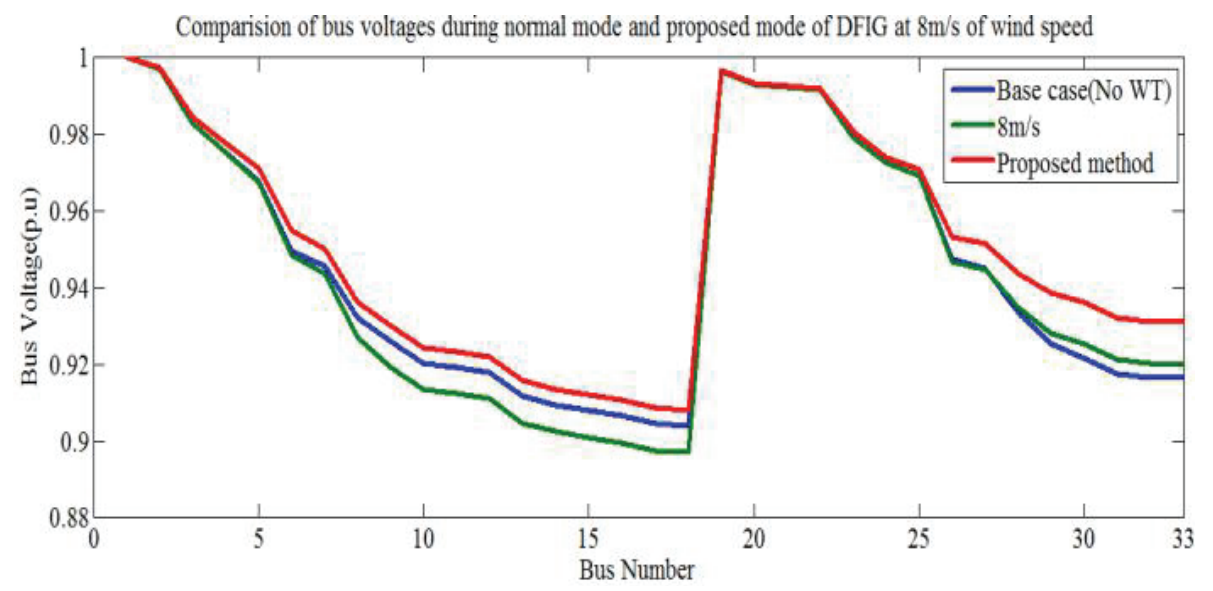

Fig. 7 Comparison of bus voltages during normal mode and reactive power control mode of DFIG (Scenario 1).

Table 8 Performance of the system during different wind speeds for proposed method in scenario 1 and scenario 2.

\begin{tabular}{llllll}
\hline Scenario & $\begin{array}{l}\text { Optimal location } \\
\text { (bus) }\end{array}$ & Min voltage & Min voltage bus & Voltage at DG bus & Power loss (kW) \\
\hline No DG & ------ & 0.9036 & 18 & -------- & 211 \\
Scenario1 & 8.29 & 0.9101 & 18 & 0.9366, & 168 \\
Scenario2 & 6 & 0.9150 & 18 & 0.9401 & 160 \\
\hline
\end{tabular}

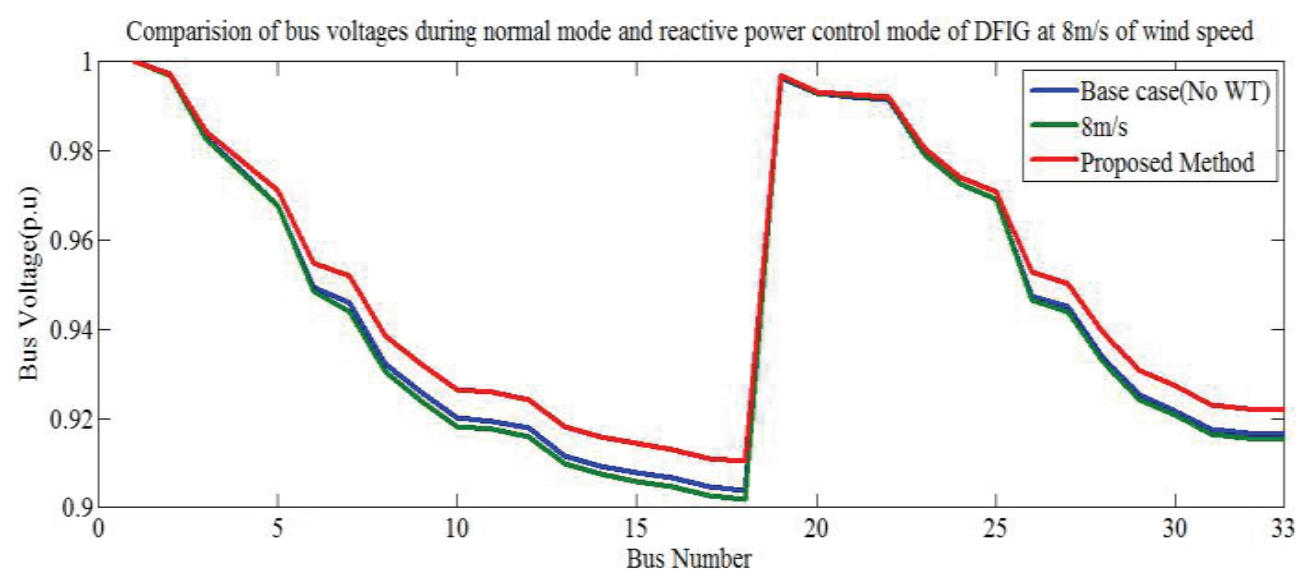

Fig. 8 Comparison of bus voltages during normal mode and reactive power control mode of DFIG (Scenario 2)

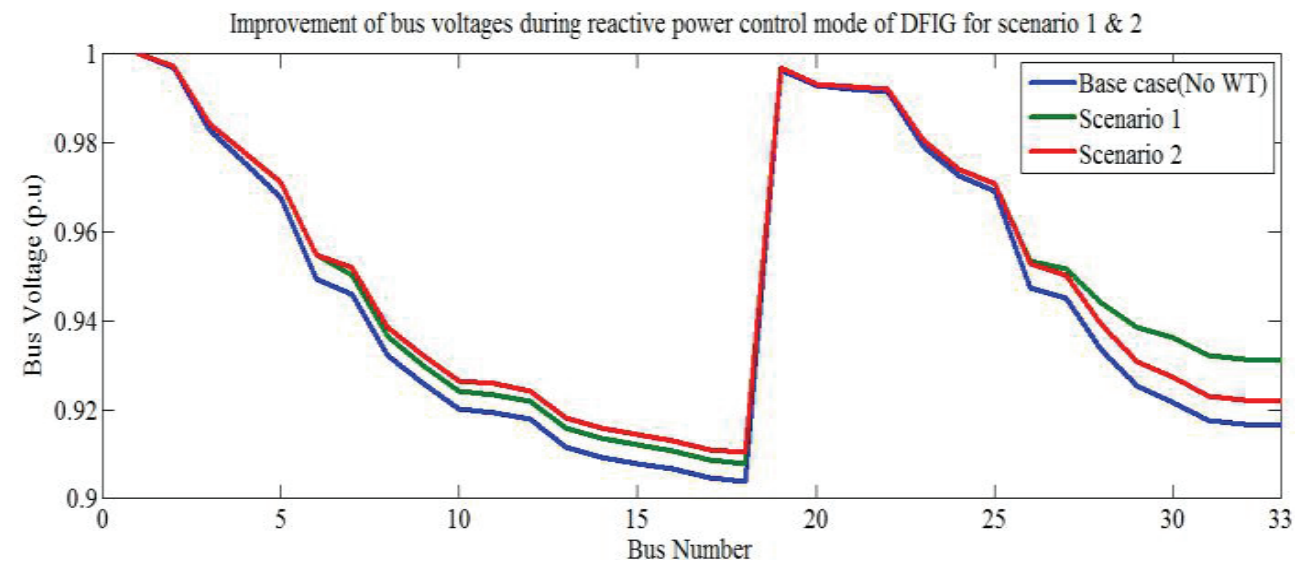

Fig. 9 Comparison of bus voltages during reactive power control mode of DFIG during scenario $1 \& 2$. 
Capabilities of DFIG under Varying Wind Speeds

Table 9 Effect on neighbouring buses in scenario 1.

\begin{tabular}{|c|c|c|c|c|c|}
\hline DG name & DG Bus & Neighbouring Bus number & Base case voltage & Voltage at $8 \mathrm{~m} / \mathrm{s}$ & $\begin{array}{l}\text { Voltage in the } \\
\text { proposed mode }\end{array}$ \\
\hline \multirow{6}{*}{ SEIG } & \multirow[t]{6}{*}{8} & 5 & 0.9679 & 0.9677 & 0.9712 \\
\hline & & 6 & 0.9495 & 0.9485 & 0.9547 \\
\hline & & 7 & 0.9459 & 0.9436 & 0.9512 \\
\hline & & 9 & 0.9260 & 0.9191 & 0.9344 \\
\hline & & 10 & 0.9203 & 0.9134 & 0.9287 \\
\hline & & 11 & 0.9194 & 0.9125 & 0.9234 \\
\hline \multirow{6}{*}{ DFIG } & \multirow[t]{6}{*}{29} & 26 & 0.9475 & 0.9468 & 0.9534 \\
\hline & & 27 & 0.9450 & 0.9447 & 0.9561 \\
\hline & & 28 & 0.9335 & 0.9350 & 0.9439 \\
\hline & & 30 & 0.9217 & 0.9254 & 0.9363 \\
\hline & & 31 & 0.9176 & 0.9212 & 0.9322 \\
\hline & & 32 & 0.9164 & 0.9203 & 0.9313 \\
\hline
\end{tabular}

Table 10 Effect on neighbouring buses in scenario 2.

\begin{tabular}{lllll}
\hline WT Bus & Neighbouring Bus number & Base case voltage & Voltage at $8 \mathrm{~m} / \mathrm{s}$ & $\begin{array}{l}\text { Voltage in the proposed } \\
\text { mode }\end{array}$ \\
\hline 3 & 0.9829 & 0.9828 & 0.9845 \\
4 & 0.9754 & 0.9761 & 0.9780 \\
5 & 0.9679 & 0.9689 & 0.9715 \\
7 & 0.9459 & 0.9441 & 0.9524 \\
6 & 0.9323 & 0.9337 & 0.9441 \\
9 & 0.9260 & 0.9274 & 0.9410 \\
26 & 0.9475 & 0.9488 & 0.9532 \\
27 & 0.9450 & 0.9462 & 0.9506 \\
\hline
\end{tabular}

In the proposed method, bus 26 is highly benefited compared to other buses because it receives power from both SEIG and DFIG. In Scenario 2 when SEIG is acting as a reactive load, buses 3, 4 and 5 are not much affected. The influence is mainly on the buses 7 , 8 and 9 and voltages at these buses drop to low value as shown in Table 10. Since bus 6 has a lateral, the voltage of buses 26,27 and 28 is also affected as shown in Table 10. During proposed mode of operation buses 5, 7, 8 and 9 are benefited much and voltage is within the specified limit. The voltage of the buses connected in lateral is also improved as shown in Table 10. In both scenarios it is seen that some bus voltages are still below the 0.95 p.u value. This is because the active power injected by both the generators is reduced due to reduction of wind speed and also converter rating for DFIG considered in this analysis is only $30 \%$ of total power rating. The bus voltages can be increased further by either increasing the number of generators or by increasing the rating of converters to $50 \%$ of generator rating [11]. As the rating of rotor side converters increases reactive power supplying capability of DFIG also increases [12] and is capable of supplying SEIG and network reactive power requirements.

\subsection{Results}

The injection of WT in both Scenarios has significant effect on network to which it is connected. The effect is mainly on voltage profile and power loss.

\subsection{Voltage Profile}

When wind speed starts reducing SEIG at bus 8 reaches to state of voltage collapse and it tries to draw reactive power from network, making this a burden to 

Capabilities of DFIG under Varying Wind Speeds

the system. In case of DFIG, it draws some additional power from network and produces active power at a rated voltage. This condition of reactive power load on network shows a negative impact on network. In practice when wind speed is less than cut in speed, SEIG is disconnected from a bus to avoid network voltage drop. But with method proposed, during low wind speeds DFIG changes its characteristics as a reactive source and supplies reactive power necessary by SEIG to encounter the voltage collapse. When wind is at rated value the voltage profile of the system is in stable region for both scenario 1 and 2. In the scenario 1 at wind speed of $8 \mathrm{~m} / \mathrm{s}$, buses nearer to SEIG bus are much affected and during proposed mode also buses nearer to bus 8 are highly benefited. There is no noticeable effect on buses nearer to DFIG in both the scenarios. In the scenario 2 when two generators are connected to same bus, during wind speed of $8 \mathrm{~m} / \mathrm{s}$ voltage drop at WT bus is less compared to scenario 1 because DFIG is injecting active power. The effect on neighbouring bus voltages is also less compared to scenario1.

\subsection{Power Loss}

When a WT is injected into network at optimal location the power loss decreased drastically. When wind speed is reducing, reactive power requirement of SEIG makes the system unstable and increases power loss. In the scenario 1 at wind speed of $8 \mathrm{~m} / \mathrm{s}$ when SEIG at bus 8 is drawing reactive power, power loss at this bus is very high compared to power loss at bus 29 , increasing total power loss. During reactive power control mode when SEIG is drawing reactive power and DFIG supplying the reactive power, the power loss is more at both buses. In the Scenario 2 power loss is very high when SEIG is drawing reactive power without compensation, but when DFIG is supplying reactive power requirement locally, the power loss is reduced to a low value compared to previous scenario. It is concluded that power loss is considerably reduced in both the scenarios 1 and 2 .

\section{Conclusion}

In this paper a new approach for voltage control of SEIG with reactive power handling capabilities of DFIG is modeled and tested on standard IEEE 33 bus system. Two possible cases have been considered for location of DFIG, one of which is connecting two generators at different buses and the other is connecting two generators at same bus. The effect on the system in both cases is thoroughly examined in this paper and it is observed that, generating capability of SEIG is enhanced from wind speed of $12 \mathrm{~m} / \mathrm{s}$ to $8 \mathrm{~m} / \mathrm{s}$. The results show that during normal operation at rated wind speed, in scenario 1 voltage profile is improved and power loss in the system decreases. During proposed method of supplying reactive VAr's to SEIG from DFIG, scenario 2 shows better performance both in voltage profile improvement and reduction of power loss. From results it is observed that proposed method demonstrates the reactive power handling capabilities of DFIG effectively. The choice placing two generators at same bus gives satisfactory results in case of voltage and power loss leading to overall stability improvement of the system. During normal operation, combination of two generators successfully aids voltage stability and reduces power loss of the system. During low wind speed or fault conditions also coordinated control between these two generators can protect the system from voltage drop and aid the network security without any additional equipment, thereby reducing the operating cost. The proposed method can also be extended to multi-machine power networks considering system faults.

\section{References}

[1] Holdsworth, L., Wu, X. G., Ekanayake, J. B., and Jenkins N. 2003. "Comparison of Fixed-Speed and Doubly-Fed Induction Generator Wind Turbines during Power System Disturbances." IEE Proc. Gener. Transm. Distrib 150 (3): 343-35.

[2] Kulshani, S., Solanki, J., and Sulz, M. N. 2000. "Development of Three-Phase Unbalanced Power Flow Using PV and PQ Models for Distributed Generation and Study of the Impact of DG Models." IEEE Trans. Power 
Syst. 22 (3): 1019-25.

[3] Peças, J. A., Maciel, F. P., and Cidras J. 1991. "Simulation of MV Distribution Networks with Asynchronous Local Generation Sources." In Proc. IEEE Malecom, Jun. 1991.

[4] Divya, K. C., and Rao, P. S. N. 2006. "Models for Wind Turbine Generating Systems and Their Application in Load Flow Studies." Electric Power Syst. 76: 844-56.

[5] Zhiqun, W., Shouzhen, Z., and Shuangxi, Z. 2004. "Impacts of Distributed Generation on Distribution System Voltage Profile." Automation of Electric Power System 28 (16): 56-60.

[6] Perdana. 2008. "Dynamic Models of Wind Turbines." Ph.D. dissertation, Chalmers Univ. Technol., Göteborg, Sweden.

[7] Eminoglu, U., Dursun, B., and Hocaoglu, M. H. 2008. "Incorporation of a New Wind Turbine Generating System Model into Distribution Systems Load Flow Analysis." Wind Energy, 375-90.

[8] Medina, M., Qi, L., and Butler, K. L. 2003. "A Three-Phase Load Flow Algorithm for Shipboard Power Systems (SPS)." In Proc. IEEE Power Eng. Soc. Transmission and Distribution Conf. Expo. 1: 227-33.

[9] Ullahand, N. R., and Thiringer, T. 2007. "Variable Speed Wind Turbines for Power System Stability Enhancement." IEEE Trans. Energy Conver. 22 (1): 52-60.

[10] Kayikci, M., and Milanovic, J. V. 2007. "Reactive Power Control Strategies for DFIG Based Plants." IEEE Trans. Energy Convers. 22 (2): 389-96.

[11] Pena, C. J. C., and Asher, G. M. 1996. "Doubly Fed Induction Generator Using Back-to-Back PWM Converters and Its Application to Variable-Speed Wind-Energy Generation.” IEE Proc. Electr. Power Appl. 143 (3): 231-41.

[12] Meeghapola, L., Fox, B. T., and Littler, F. D. 2013. "Multi Objective Reactive Power Flow from Wind Farms for Network Performance Enhancement." Int. Trans. Electr. Energ. Syst. on Energy Conversion 23: 135-50.

[13] Hasan, A. M., and Wu, B. 2010. "Comparison of
Stabilization Methods for Fixed-Speed Wind Generator Systems." IEEE Trans. on Power Delivery 25 (1).

[14] Kheldoun, A., Refoufi, L., and Eddine, D. 2012. "Analysis of the Self-Excited Induction Generator Steady State Performance Using a New Efficient Algorithm." Journal of Electr. Power Syst. 86: 61-7.

[15] Padron, J. F. M., and Lorenzo, A. E. F. 2010. "Calculating the Steady-State Operating Conditions for Doubly-Fed Induction Generator Wind Turbines." IEEE Trans. on Power Systems 25: 922-8.

[16] Dadhani, A., Venkatesh, B., Nassif, A. B., and Sood, V. K. 2013. "Modelling of Doubly fed Induction Generators for Distribution system Power Flow Analysis." Electric Power and Energy Systems 53: 576-83.

[17] Murthy, V. V. S. N., and Aswani, K. 2013. "Comparison of Optimal DG Allocation Methods in Radial Distribution Systems Based on Sensitivity Approaches.” Int. J. Electr. Power Energy Syst. 53: 450-67.

[18] Satish, K., Vishal, K., and Bajeev, T. 2013. "Optimal Placement of Different Types of DG Sources in Distribution System." Int. J. Electr. Power Energy Syst. 53: 752-60.

[19] Partha, K., and Chanda, C. K. 2013. "Placement of Wind and Solar Based DGs in Distribution System for Powerloss Minimization and Voltage Stability Improvement." Int. J. Electr. Power Energy Syst. 53: 795-809.

[20] Mithulananthan, N., Tha, O., and Phu, L. V. 2004. "Distributed Generator Placement in Power Distribution System Using Genetic Algorithm to Reduce Losses." Int. J. Sc. Tech. 9 (3).

[21] El-Zonkoly, A. M. 2011. "Optimal Placement of Multi-Distributed Generation Units Including Different Load Models Using Particle Swarm Optimisation." IET Gener. Transm. Distrib. 5 (7): 760-71.

[22] Hung, D. Q., Mithulananthan, N., and Lee, K. Y. 2014. "Optimal Placement of Dispatchable and Non-dispatchable Renewable DG Units in Distribution Networks for Minimizing Energy Loss." Int. J. Electr. Power Energy Syst. 55: 179-86. 
Appendix

Induction of Machine Parameters

The parameters of the induction machine considered given below are taken from Ref. [16].

\begin{tabular}{ll}
\hline Wound rotor induction machine stator/grid voltage $\mathrm{V}_{\mathrm{S}}(\mathrm{r} \cdot \mathrm{m} \cdot \mathrm{s} \cdot \mathrm{L}-\mathrm{L})$ & $2,400 \mathrm{~V}$ \\
Nominal power Pn: $2,250 \mathrm{hp} * 746 \mathrm{VA}$ & $1.6 \mathrm{MVA}$ \\
Nominal phase voltage V (Per Phase) & $1,368 \mathrm{~V}$ \\
Nominal frequency $(\mathrm{f})$ & $50 \mathrm{~Hz}$ \\
Stator resistance $\left(\mathrm{R}_{\mathrm{s}}\right)$ & $0.029 \Omega$ \\
Stator inductance $\left(\mathrm{L}_{\mathrm{sl}}\right)$ & $0.226 / 377 \mathrm{H}$ \\
Rotor resistance $\left(\mathrm{R}_{\mathrm{r}}\right)$ & $0.022 \Omega$ \\
Rotor inductance $\left(\mathrm{L}_{\mathrm{rl}}\right)$ & $0.226 / 377 \mathrm{H}$ \\
Mutual inductance $\left(\mathrm{L}_{\mathrm{ml}}\right)$ & $13.04 / 377 \mathrm{H}$ \\
Inertia coefficient $(\mathrm{J})$ & 63.87 \\
Pole pairs $(\mathrm{P})$ & 2 \\
Pitch angle $(\beta)$ & $0 \mathrm{degree}$ \\
Data Nominal mechanical output power $\left(\mathrm{P}_{\text {nom }}\right)$ & $1.5 \mathrm{MW}$ \\
Base power of the electrical generator $\left(\mathrm{S}_{\mathrm{b}}\right)$ & $2,250 \mathrm{hp}$ \\
Base wind speed $\left(\omega_{\text {base }}\right)$ & $14 \mathrm{~m} / \mathrm{s}$ \\
Max. power at base wind speed (p.u. of nominal mech. power) & 0.73 \\
Base speed (p.u. of base generator speed) & 1.2 \\
Excitation capacitance (each phase) $(\mathrm{C})$ & $68 \mu \mathrm{F}$
\end{tabular}

The parameters in Eq. (1) are given below:

$$
\begin{gathered}
L_{1}=X_{s}\left(X_{r}+X_{m}\right)+X_{r} X_{m} \\
L_{2}=X_{r}+X_{m} \\
L_{3}=X_{s}+X_{m}
\end{gathered}
$$

Genetic algorithm parameters [20]:

The weights of the fitness function $\mathrm{W}_{\mathrm{p}}=0.35, \mathrm{~W}_{\mathrm{q}}=0.1, \mathrm{~W}_{\mathrm{v}}=0.55$

Crossover method: Single point cross over

Population size $=100$

Crossover rate: 0.9

Mutation rate: 0.035

The line and load data of the 33 bus radial distribution test system are taken from Ref. [4]. The total system load is 3.715 MW and 2.3 MVAr. 